\title{
EFEITO DOS DANOS DE PÁSSAROS SOBRE A QUALIDADE DE SEMENTES DURANTE A MATURAÇÃO DE AVEIA PRETA
}

\author{
João Nakagawa ${ }^{1,2}$ \\ Cláudio Cavariani ${ }^{1}$
}

\section{RESUMO}

Para avaliar o efeito dos danos ocasionados por pássaros durante a maturação de sementes de aveia preta (Avena strigosa Schreber) foram conduzidos dois experimentos em condições de campo em Botucatu-SP. A maturação foi acompanhada através de colheitas realizadas semanalmente, a partir da data de emergência das panículas. $O$ ataque de aves passeriformes da família dos fringilídeos, predominantemente papa-capins, ocorreu quando as espiguetas encontravam-se nos estádios leitoso a farináceo. As panículas atacadas pelos pássaros apresentaram sementes danificadas com menor peso de matéria seca, germinação e vigor.

Palavras-chave: aveia preta, maturação, dano por pássaros, qualidade de sementes, Avena strigosa.

\section{ABSTRACT}

\section{EFFECTS OF BIRD DAMAGE ON SEED QUALITY DURING MATURATION OF BLACK OAT.}

Two experiments were carried out under field conditions aiming to evaluate the bird damage during seed maturation of black oat (Avena

'Faculdade de Ciências Agronômicas, UNESP/Botucatu, Caixa Postal 237, 18603-970Botucatu/SP, Brasil.

2Professor Voluntário/Bolsista do CNPq. 
strigosa Schreber), in Botucatu county, São Paulo State, Brazil. The maturation of the seeds was evaluated by weekly harvest, beginning at the panicle emergence. The small birds of Fringilidae attacked the panicles when the cariopsis usually were in the milk stage up to the farinaceous stage. The panicles attacked by the small birds showed damaged seeds with lower dry matter, germination and vigour.

Key words: maturation, bird damage, seed quality, Avena strigosa.

\section{INTRODUÇÃO}

A aveia preta (Avena strigosa Schreber) é uma gramínea empregada como forrageira de inverno e como material para adubação verde de inverno, na região sul do país e no Estado de São Paulo, com bons resultados (Derpsch, 1984; Medeiros et al., 1984; Salerno \& Vetterle, 1984. Derpsch et al., 1985; Trani et al., 1989). É utilizada para rotação de culturas, em alternativa ao trigo (Santos, 1991) e para sistema de semeadura direta, por ser produtora de grande quantidade de massa e pela sua capacidade de diminuir a infestação de invasoras (Derpsch \& Calegari, 1992).

As sementes de aveia preta apresentam maturação desuniforme, havendo diferenças entre plantas, entre as panículas da planta e entre as espiguetas da panícula (Nakagawa, et al., 1994a, 1994b), o que ocasiona atraso na colheita à espera da maturidade do campo, ficando assim as sementes mais sujeitas a ação negativa do ambiente, tanto a fatores bióticos como abióticos. As culturas de aveia, por outro lado, normalmente amadurecem um pouco defasadas em relação aos outros cereais de inverno, o que as torna mais expostas ao ataque de bandos de pequenas aves passeriformes, durante a fase de formação dos grãos. Para estas aves as inflorescências nos primeiros estádios de maturação, da fase leitosa a farinácea, são mais atrativas, enquanto os pássaros maiores, como as pombas (ordem Columbiformes) e corvos (família Corvídeo), predam as aveias derrubando os grãos e alimentando-se deles no solo (Clifford, 1995). Outros cereais, como arroz, sorgo e trigo (Graner \& Godoy Junior, 
1967; Almeida \& Canecchio Filho, 1987) e o girassol (Ungaro, 1987) estão também sujeitos ao ataque de diferentes pássaros na fase final de maturação dos grãos, recomendando-se as colheitas antecipadas para evitarem-se os prejuízos ocasionados por eles.

Os pássaros não consomem os grãos quando as glumas são longas e as aristas compridas, sendo que o tipo de panícula, se compacta e firme ou ramificada e frouxa, pode também interferir na predação pela facilidade de pouso na panícula ou de retirada dos grãos desta (Quinby \& Schertz, 1975). Para proteger as culturas do ataque de pássaros têm sido empregados vários equipamentos visuais, sonoros ou mecânicos, com graus variáveis de sucesso (Clifford, 1995), ou ainda, para pequenas áreas experimentais, a realização de isolamento, com telados ou redes de náilon para cobertura, tem sido a solução (Rachie, 1975). Pode-se ainda utilizar repelentes químicos, tanto em sementes, para evitar danos na fase de semeadura/germinação (Avery et al., 1998), como na cultura em crescimento (Rachie, 1975, Clifford, 1995).

Considerando estas informações da literatura, o objetivo deste trabalho foi estudar o efeito dos danos de pássaros sobre a qualidade física e fisiológica das sementes, durante a maturação das panículas de aveia preta.

\section{MATERIAL E MÉTODOS}

O trabalho foi conduzido com a aveia preta (Avena strigosa Schreber) cv. Comum, parte em condições de campo, em solo classificado como Terra Roxa Estruturada distrófica, textura argilosa (Carvalho et al., 1983), pertencente à Fazenda Experimental Lageado do Câmpus de Botucatu, UNESP, em Botucatu-SP, e parte em laboratório. Constou de dois experimentos, $\mathrm{E}_{1} \mathrm{e}$ $\mathrm{E}_{2}$, instalados para estudo de maturação das panículas por meio de coletas semanais, após a emissão delas, nas quais ocorreu o ataque de aves Passeriformes da família Fringilídeos (Thering, 1968), predominantemente papa-capins, a partir da terceira coleta em $\mathrm{E}_{1}$ e da segunda $\mathrm{em}_{2}$. 
A calagem e a adubação foram feitas com base nos resultados de análise química de solo e nas recomendações encontradas nas Instruções Agrícolas para o Estado de São Paulo (Instituto Agronômico, 1986) para aveia (Avena sativa L.).

As semeaduras foram realizadas aos 20/04/90 $\left(E_{1}\right)$ e 17/05/90 ( $\left.E_{2}\right)$, manualmente, empregando-se espaçamento entre linhas de $0,20 \mathrm{~m}$ e densidade de 40 sementes, por metro de sulco. Os tratos culturais constaram do controle de plantas daninhas, manualmente.

As panículas que se apresentavam inteiramente recém-emergidas das folhas bandeira, foram etiquetadas em um só dia, respectivamente aos 08/08/90 $\left(E_{1}\right)$ e 12/09/90 $\left(E_{2}\right)$. As coletas, iniciadas nas datas da etiquetagem, foram oito em $E_{1}$ e sete em $E_{2}$; no experimento $E_{2}$ foi realizada uma oitava coleta de panículas não etiquetadas, que não apresentavam danos ocasionados pelo ataque dos pássaros.

Em cada coleta foram colhidas ao acaso 50 panículas etiquetadas em todas as épocas de $E_{1}$ e nas sete primeiras de $E_{2}$; na oitava coleta de $E_{2}$ foram colhidas 25 panículas contínuas em cinco pontos distintos da área, totalizando 125 panículas.

Após cada colheita, nos dois experimentos, as panículas foram levadas imediatamente ao laboratório, no interior de sacos plásticos bem vedados, e a seguir retiradas amostras de sementes para determinação do teor de água pelo método da estufa a $105^{\circ} \mathrm{C}$ por $24 \mathrm{~h}$ (Brasil, 1976). Foram empregadas quatro amostras de 50 sementes para esta determinação, sendo estas utilizadas para a obtenção dos pesos de matéria seca de 100 sementes, com e sem glumas. Nesta ocasião foram examinadas as espiguetas quanto ao estádio de desenvolvimento e a ocorrência de ataque de pássaros.

No experimento $\mathrm{E}_{2}$, as sementes, após separadas das panículas, foram postas a secar na sombra e decorrido em torno de um mês após a colheita foram submetidas à determinação do teor de água (Brasil, 1976) e ao teste de germinação. $O$ teste de germinação foi realizado com quatro repetições de 50 sementes; as condições do teste, bem como a avaliação de plântulas, seguiram as prescrições e recomendações para aveia (Avena 
sativa L.) das Regras para Análise de Sementes (Brasil, 1976). Foram determinadas a porcentagem de germinação (total de plântulas normais), porcentagem de sementes germinadas (somatória do total de plântulas normais e de plântulas anormais) e o vigor das sementes (plântulas normais na primeira contagem).

As características avaliadas de cada experimento foram analisadas separadamente, considerando delineamento inteiramente casualizado, com oito tratamentos (coletas) e quatro repetições. Os dados em porcentagem foram transformados em $\mathrm{y}=\operatorname{arcsen}(\mathrm{x} / 100)^{1 / 2} \mathrm{e}$ as características que apresentaram alguns valores zero, em $y=(x+0,5)^{1 / 2}$ antes de serem submetidos à análise de variância; e as médias foram comparadas pelo teste Tukey ao nível de 5\% de probabilidade (Pimentel-Gomes, 1973). Os dados apresentados nas tabelas estão em seus valores originais.

\section{RESULTADOS E DISCUSSÃO}

No experimento $E_{1}$, por ocasião da primeira coleta, isto é no dia da etiquetagem, as panículas apresentavam-se todas verdes, com as espiguetas do ápice em estádio aquoso e as das regiões mediana e basal com flores; o teor de água estava bem elevado (Tabela 1) e $36 \%$ do peso da matéria seca das sementes era representada pelas glumas. No decorrer das coletas, com a maturação, os valores do teor de água foram diminuindo gradativamente, com maior queda entre 28 e 35 dias após a emissão da panícula (DAEP), para a seguir estabilizarem-se.

Os pesos de matéria seca de 100 sementes, com e sem glumas, foram crescentes até a terceira coleta (Tabela 1), ocasião em que foi constatado o início do ataque de pássaros. Neste momento, as panículas coletadas estavam verdes, com as espiguetas do ápice predominantemente em estádio pastoso e as porções mediana e basal leitoso, com alto teor de água. As espiguetas mais predadas encontravam-se nos ápices das panículas, vindo a confirmar que a preferência dos passeriformes, no presente caso da família Fringilídeos (papa-capins, principalmente), é dos grãos de aveia em formação, nos primeiros estádios, de leitoso a farináceo (Clifford, 1995). 
Tabela 1. Dados médios de peso de matéria seca de 100 sementes (g), com e sem glumas, e teor de água das sementes por ocasião das coletas, obtidos em função das épocas de coletas e dos danos por pássaros em aveia preta no decorrer da maturação das sementes. Experimento $\mathrm{E}_{1}$. Botucatu, 1990.

\begin{tabular}{cccc}
\hline Tratamentos & \multicolumn{2}{c}{ Peso de matéria seca de 100 sementes $(\mathrm{g})$} & \\
\cline { 2 - 3 } Coleta (DAEP) & Com glumas & Sem glumas & Teor de água (\%) \\
\hline $1(0)$ & $0,5260 \mathrm{~d}^{2}$ & $0,3364 \mathrm{~d}$ & $67,7 \mathrm{a}$ \\
$2(7)$ & $0,7829 \mathrm{bc}$ & $0,5779 \mathrm{c}$ & $62,1 \mathrm{~b}$ \\
$3(14)^{3}$ & $1,1294 \mathrm{a}$ & $0,8256 \mathrm{ab}$ & $57,1 \mathrm{c}$ \\
$4(21)^{3}$ & $0,9288 \mathrm{~b}$ & $0,6941 \mathrm{bc}$ & $48,9 \mathrm{~d}$ \\
$5(28)^{3}$ & $1,1951 \mathrm{a}$ & $0,9678 \mathrm{a}$ & $39,5 \mathrm{e}$ \\
$6(35)^{3}$ & $0,9198 \mathrm{~b}$ & $0,6978 \mathrm{bc}$ & $14,6 \mathrm{f}$ \\
$7(42)^{3}$ & $0,7286 \mathrm{c}$ & $0,5423 \mathrm{c}$ & $12,4 \mathrm{f}$ \\
$8(49)^{3}$ & $0,7962 \mathrm{bc}$ & $0,5812 \mathrm{c}$ & $14,0 \mathrm{f}$ \\
\hline $\mathrm{C} \mathrm{V}$ & $8,16 \%$ & $12,04 \%$ & $2,41 \%$ \\
\hline
\end{tabular}

'Dias após emergência completa da panícula.

${ }^{2}$ Médias, na coluna, seguidas da mesma letra não diferem entre si significativamente, pelo teste Tukey, ao nível de $5 \%$ de probabilidade.

${ }^{3}$ Com danos por pássaros.

É interessante salientar que apesar de a aveia preta apresentar arista relativamente longa, não constitui barreira ao ataque destes passeriformes, como tem sido relatado como sendo para cultivares de sorgo e trigo com aristas longas (Graner \& Godoy Junior, 1967; Quinby $\&$ Schertz, 1975). De forma semelhante, a panícula da aveia preta, ramificada e aparentemente frouxa, que são consideradas características não favoráveis ao pousio na panícula em cultivares de sorgo (Quinby \& Schertz, 1975), não representa obstáculo para estes passeriformes realizarem a predação.

As espiguetas atacadas apresentavam os ápices descoloridos, que passaram a amarelo/palha e a seguir secos, embora a base destas encontrassem ainda, muitas vezes, verdes, com aspecto de má formação, devido ao consumo do conteúdo da cariópse pelos pássaros. 
Os pesos de matéria seca de 100 sementes, com e sem glumas, a partir da terceira coleta (14 Daep) em vez de aumentarem, no decorrer da maturação, como observaram Nakagawa et al. (1994b), em trabalho semelhante, passaram a apresentar valores iguais ou menores nas coletas seguintes, como resultado do dano dos pássaros, consumindo o material acumulado nas sementes. Comparando os valores obtidos neste experimento $E_{1}$ (Tabela 1), com os de $E_{2}$ (Tabela 2), que também sofreu ataque de pássaros, e com os relatados por Nakagawa et al., (1994) (com valores de matéria seca de 100 sementes, sem glumas, variando de 1,3440 a $1,8872 \mathrm{~g}$ ), observou-se que as perdas em matéria seca das sementes provenientes de panículas atacadas foram de mais de dois terços du que seria acumulado. As coletas foram semanais.

A partir da sexta coleta (35 DAEP), observa-se que os valores dos pesos de 100 sementes, com e sem glumas, foram semelhantes aos da quarta (21 DAEP), (Tabela 1), levando isto a inferir que os danos observados naquela coleta (sexta) e nas seguintes haviam ocorrido quando os teores de água eram maiores ou seja com as espiguetas em estádios pastoso/farináceo, de acordo com o relatado para aveia (Clifford, 1995), e não após estarem secas e duras.

No experimento $\mathrm{E}_{2}$, os aspectos das panículas e das espiguetas por ocasião da primeira coleta eram semelhantes aos do $E_{1}$. $O$ ataque de pássaros iniciou na segunda coleta (7 DAEP), quandó todas as pa:íículas coletadas estavam verdes, com as espiguetas do ápice em estádio leitoso, as da região mediana aquosa e as da base ainda em flor, estando o teor de água bastante elevado (Tabela 2). A queda do teor de água das sementes no decorrer das coletas foi contínua à semelhança do ocorrido no experimento $\mathrm{E}_{1}$, exceção na sexta coleta (35 DAEF), quando houve aumento, em função das chuvas ocorridas $(23 \mathrm{~mm})$ nos dias anteriores à coleta.

Pelas médias dos pesos de matéria seca de 100 sementes, com e sem glumas, observa-se que apesar do ataque dos pássaros ter-se iniciado antes neste experimento em relação ao anterior, os danos foram menores (Tabelas 1,2), pois podem-se constatar acréscimos dos valores com o decorrer das coletas, o que indica acúmulo de matéria seca das semen- 
tes com exceção da sexta coleta, feita após a chuva. Desta forma, os pesos de matéria seca de 100 sementes da sétima coleta (panículas etiquetadas), com ataque de pássaros, foram semelhantes ao da oitava coleta (panículas não etiquetadas), sem ataque de pássaros (Tabela 2). Neste experimento, examinando-se as espiguetas das panículas atacadas, pode-se constatar que as do terço superior, predominantemente as do ápice das ráquilas, eram as que se mostravam com danos.

Esta menor intensidade de ataque e danos dos passeriformes no experimento $E_{2}$, com semeadura um mês após o $E_{1}$, deve ter sido resultado do aumento de área disponível de grãos tanto de aveia preta como de outros cereais de inverno diluindo o efeito do ataque das aves.

Apesar dos efeitos no peso da matéria seca não terem sido, aparentemente tão significativos, verifica-se, entretanto, que a germinação das sementes com o decorrer da maturação não aumentou continuamente como observado em estudo semelhante com aveia preta (Nakagawa et al., 1994b) e os valores obtidos foram menores (Tabela 2). Isto indica que os danos ocasionados pelos pássaros afetaram a qualidade fisiológica das sementes. Assim, comparando-se o resultado da germinação das sementes da sétima coleta com o da oitava, verifica-se que esta, sem danos por pássaros, apresentou valor superior às com danos, apesar da semelhança dos pesos de matéria seca das sementes (Tabela 2).

Os dados de porcentagem (x) de Sementes Germinadas foram estudadas por análise de variância e regressão polinomial após transformação de cada parcela pela fórmula $y=\operatorname{arcoseno} \sqrt{x / 100}$. A regressão foi levada até o terceiro grau, com equação:

$$
\mathrm{Y}_{1}=2,089+16,85 \mathrm{X}-4,179 \mathrm{X}^{2}+0,4257 \mathrm{X}^{3}
$$

com X (ordem de coleta - 1) $=0,1,2, \ldots, 7$. Embora os coeficientes todos fossem significativos ao nível de $1 \%$ de probabilidade e tivéssemos $R^{2}=96,8 \%$, verificou-se, pelo cálculo dos valores assumidos pela equação, que ela na verdade não representa bem os dados em estudo. Em 


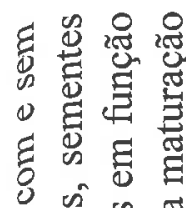

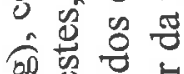

象

语

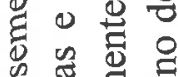

8 造

일

证

苋

贾

范

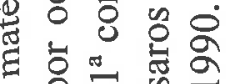

吃司

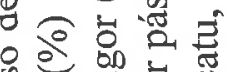

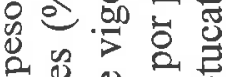

制。

둥ㅇㅇㅇ

प

保证

言密

ㄴ. 묘

㗪署

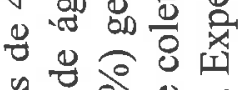

$\because 50$ क

可骂骂

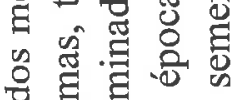

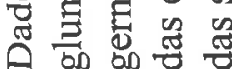

ปั่

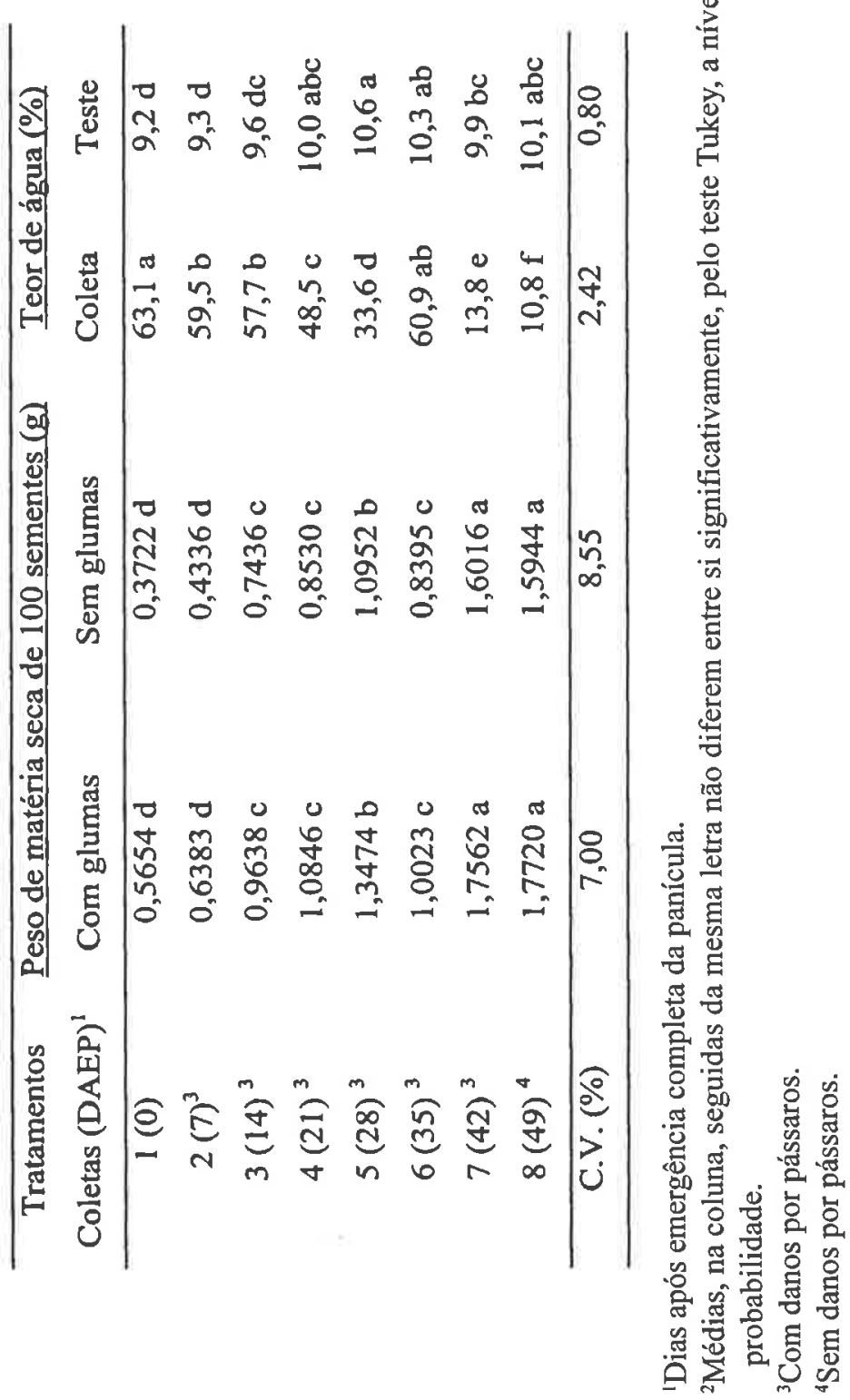


vista disso, abandonou-se a equação de regressão e aplicou-se o teste de Tukey com base na análise da variância dos dados transformados (Tabela 3) e nas médias de coletas respectivas (Tabela 5).

No que se refere às porcentagens $(x)$ de Germinação, o procedimento, semelhante, levou ao abandono da equação de regressão. Mas neste caso a primeira coleta, que só deu valores nulos para $\mathbf{x}$, foi abandonada. A análise da variância para os dados transformados consta da Tabela 4 e o valor de $\Delta$ (Tukey a $5 \%$ ) deu $\Delta=8,59$ graus (Tabela 6).

No caso do Vigor ( $1^{\text {a }}$ contagem $)$ a análise da variância e o teste de Tukey aplicados às três últimas coletas $(6,7$ e 8) com os dados transformados pela fórmula $\mathrm{y}=\operatorname{arcoseno} \sqrt{x / 100}$, deu os resultados expostos na Tabela 5.

Este efeito prejudicial do dano do pássaro sobre a qualidade fisiológica é mais bem observado ao se examinar os dados de sementes germinadas $(\%)$ e de vigor $\left(1^{a}\right.$ contagem, $\%$ ) (Tabela 5 ). As sementes germinadas aqui consideradas, representavam a soma do total de plântulas normais e plântulas anormais, portanto, quanto maior foi a diferença entre sementes germinadas e germinação, significa menor vigor, pois significa que as sementes germinaram mas não formaram plântulas normais. Em todas as coletas, as panículas atacadas por pássaros mostraram maior porcentagem de plântulas com anormalidades que as sem ataque (oitava coleta), indicando menor vigor daquelas, fato confirmado de forma bem evidente pelo vigor $\left(1^{\mathrm{a}}\right.$ contagem) (Tabela 5).

\section{CONCLUSÕES}

As panículas que sofreram ataque de pássaros na fase de maturação apresentaram sementes danificadas, com menor peso de matéria seca, germinação e vigor. 
Tabela 3. Análise da variância para as porcentagens (x) de Sementes Germinadas após transformação do valor de cada parcela pela fórmula $\mathrm{y}=\operatorname{arcoseno} \sqrt{x / 100}$ (em graus).

\begin{tabular}{lrrrc}
\hline C. de Var. & G.L. & Q.M. & F & Prob. \\
\hline Coletas & 7 & $1.350,03$ & 26,482 & 0,00000 \\
Residuo & 24 & 50,98 & & \\
\hline
\end{tabular}

$\Delta($ Tukey a $5 \%)=16,71$ graus

Tabela 4. Análise da variância para as porcentagens (x) de Germinação após transformação do valor de cada parcela pela fórmula $y=\operatorname{arcoseno} \sqrt{x / 100}$ (em graus). Foram abandonados os dados da primeira coleta, todos eles nulos.

\begin{tabular}{lrrrc}
\hline C. de Var. & G.L. & Q.M. & F & Prob. \\
\hline Coletas & 6 & 1045,42 & 59,84 & 0,00000 \\
Resíduo & 21 & 17,47 & & \\
\hline
\end{tabular}

$\Delta($ Tukey a $5 \%)=8,59$ graus

\section{REFERÊNCIAS BIBLIOGRÁFICAS}

ALMEIDA, T.C. \& V. CANECHIO FILHO, 1987. Principais Culturas. 2.ed. Campinas, Instituto Campineiro de Ensino Agrícola. 401p. AVERY, M.L.; J.S. HUMPHREY; T.M. PRIMUS; D.G. DECKER; A.P. MCGRANE., 1998. Anthraquinone Protects Rice Seed from Birds. Crop Protection, 17(3):225-230.

BRASIL, Ministério da Agricultura. Departamento Nacional de Produção Vegetal. Divisão de Sementes e Mudas. 1976. Regras para análise de sementes. [s.1.]. 188p. 
Tabela 5. Médias de y e valor correspondente de x, para Sementes Germinadas em porcentagem, após transformação.

\begin{tabular}{ccccc}
\hline Coleta & $\begin{array}{c}\text { Médias de y } \\
\text { (graus) }\end{array}$ & $\begin{array}{c}\text { Médias originais } \\
(\mathrm{x})\end{array}$ & Vigor $\left(1^{\mathrm{a}}\right.$ Contagem) \\
\hline 8 & 61,25 & $87,5 \% \mathrm{~A}$ & $67,0 \% \mathrm{~A}$ \\
7 & 42,44 & $67,0 \%$ & $\mathrm{~B}$ & $33,0 \% \mathrm{~B}$ \\
6 & 41,41 & $66,0 \%$ & $\mathrm{~B}$ & $22,0 \% \mathrm{~B}$ \\
5 & 26,12 & $44,0 \%$ & $\mathrm{BC}$ & $0,0 \% \mathrm{C}$ \\
3 & 24,17 & $40,0 \%$ & $\mathrm{C}$ & $0,0 \% \mathrm{C}$ \\
4 & 23,63 & $40,0 \%$ & $\mathrm{C}$ & $0,0 \% \mathrm{C}$ \\
2 & 17,24 & $29,5 \%$ & $\mathrm{CD}$ & $0,0 \% \mathrm{C}$ \\
1 & 0,85 & $1,5 \%$ & $\mathrm{D}$ & $0,0 \% \mathrm{C}$ \\
\hline
\end{tabular}

$\Delta=16,71$ graus (para as médias dos dados transformados ( $y$, em graus), para Sementes Germinadas.

Tabela 6. Médias de y (em graus) e valor correspondente de $\mathrm{x}$ (em porcentagem) para a Germinação.

\begin{tabular}{|c|c|c|c|}
\hline Coleta & $\begin{array}{l}\text { Médias de y } \\
\text { (graus) }\end{array}$ & $\begin{array}{l}\text { Médias originais } \\
(\mathrm{x})\end{array}$ & Vigor $\left(1^{a}\right.$ Contagem $)$ \\
\hline 8 & 57,89 & $84,5 \% \mathrm{~A}$ & \\
\hline 7 & 36,29 & $59,0 \%$ B & \\
\hline 6 & 30,73 & $51,0 \%$ BC & \\
\hline 3 & 21,83 & $37,0 \% \quad \mathrm{CD}$ & \\
\hline 5 & 18,97 & $32,5 \%$ & \\
\hline 4 & 17,16 & $29,5 \%$ & \\
\hline 2 & 8,92 & $15,5 \%$ & \\
\hline
\end{tabular}

$\Delta=8,59$ graus. 
CARVALHO, W.A.; C.R. ESPINDOLA; A.A. PACCOLA, 1983. Levantamento de Solos da Fazenda Lageado. Botucatu, Faculdade de Ciências Agronômicas, Campus de Botucatu/ UNESP. 95p. (Boletim Técnico, 1).

CLIFFORD, B.C., 1995. Diseases, Pest and Disorders of Oat. In. WELCH, R.W. The Oat Crop: Production and Utilization. London, Champman \& Hall. p.252-278.

DERPSCH, R., 1984. Alguns Resultados sobre Adubação Verde no Paraná. In: FUNDAÇÃO CARGILL. Adubação Verde no Brasil.

Campinas. p.268-279.

DERPSCH, R. \& A. CALEGARI, 1992. Plantas para Adubação Verde de Inverno. Londrina, IAPAR. 80p. (Circular, 73).

DERPSCH, R.; N. SIDIRAS; F.Z. HEINZMANN., 1985. Manejo do solo com coberturas verdes de inverno. Pesq. Agropec. Bras., 20(7):761-773. GRANER, E.A. \& C. GODOY JUNIOR., 1967. Culturas da Fazenda

Brasileira. 4.Ed. São Paulo, Edições Melhoramento, 461p. IHERING, R. von., 1968. Dicionário do Animais do Brasil. São Paulo,

Editora Universidade de Brasília. 790p.

INSTITUTO AGRONÔMICO, 1986. Instruções Agrícolas para o Es-

tado de São Paulo. 3ed. rev. atual. Campinas. 229p. (Boletim, 200). MEDEIROS, R.B.; R.A. DHEIN, L.V.M. VIAU; J.E.G. ZAMBA; W. COLOMBO; A. ANTONINI, 1984. Pesquisas em Adubação Verde e Conservação do Solo no Centro de Treinamento de Contrijui. In: FUNDAÇÃO CARGILL. Adubação Verde no Brasil. Campinas. p.292-309.

NAKAGAWA, J.; C. CAVARIANI; J.R. MACHADO., 1994a. Maturação de Sementes de Aveia Preta (Avena strigosa Schreb). I. Maturidade do Campo. Pesq. Agropec. Bras., 29(2):315-326.

NAKAGAWA, J.; C. CAVARIANI; J.R. MACHADO., 1994b. Maturação de Sementes de Aveia Preta (Avena strigosa Schreb). II. Maturidade da Panícula e da Espigueta. Pesq. Agropec. Bras., 29(2):327-339. PIMENTEL-GOMES, F., 1973. Curso de Estatística Experimental. 5ed. Piracicaba, Escola Superior de Agricultura Luiz de Queiroz / USP. 430 p. +15 tabelas. 
QUINBY, J.R. \& K.F. SCHERTZ. 1975. Genética, Fitotecnia y Produccion de Semilla de Sorgo Hibrido. In: WALL, J.S. \& W.M. ROSS. Produccion y Usos del Sorgo. Argentina, Editorial Hemisfério Sur. p.43-67.

RACHIE, K.O., 1975. El Sorgo em Asia. In: WALL, J.S. \& W.M. ROSS. Produccion y Usos del Sorgo. Argentina, Editorial Hemisfério Sur. p.185-215.

SALERNO, A.R. \& C.P. VETTERLE, 1984. Avaliação de Forrageiras de Inverno no Baixo Vale do Itajaí, Santa Catarina. Florianópolis: EMPASC. 2p. (Comunicado Técnico, 76).

SANTOS, H.P., 1991. Soja em Sucessão a Aveia Branca, Aveia Preta, Azevém e Trigo: Características Agronômicas. Pesq. Agropec. Bras., 26(9):1563-1576.

TRANI, P.E.; E.A. BULISANI; N.R. BRAGA., 1989. Adubação Verde. Campinas, Coordenadoria de Assistência Técnica Integral. 13p. (Boletim Técnico, 197).

UNGARO, M.R.G., 1987. Contribuição do IAC para a Cultura do Girassol. O Agronômico, 39(3):238-251. 